\title{
Studying the biomarker value of urine summary in diabetes - possible relevance for understudying the connections between the cognitive function decline and diabetes?
}

\author{
Iuliana Simona Luca, Mihaela Gontea, \\ Daniel Timofte, Alin Ciobîcă
}

Iuliana Simona Luca - Sf. Dimitrie Hospital, Tg, Neamt, Romania

Mihaela Gontea - Sf. Dimitrie Hospital, Tg, Neamt, Romania

Daniel Timofte - MD, PhD, professor, "Grigore T.Popa" University of Medicine and Pharmacy, 16, Iasi, Romania

Alin Ciobîcă - PhD, scientist researcher, Department of Research, Faculty of Biology, Alexandru Ioan Cuza University, Iasi, Romania, Academy of Romanian Scientists, Bucuresti, Romania,Center of Biomedical Research, Romanian Academy, Iasi

\begin{abstract}
In the present report we were interested in describing some clinical data on a comparative analysis of the summary and urinary sediment in a group of patients with well-controlled diabetes compared to a group of patients with poorly controlled diabetes. Also we do speculate here in the Discussion section on the relations between diabetes and the memory/cognitive decline and how this could be correlated for example with the most important memorydeficient disorders: the Alzheimer's disease (AD) dementia. In this way, this could be important for the understanding of diabetes and AD pathophysiology, as well as for the correlations between these two disorders, as our groups are planning to study in the near future.
\end{abstract}

KEYWORDS:

Glucose, insulin, glycosylated hemoglobin, metabolic syndromes, cognitive function, memory, Alzheimer's disease.

\section{INTRODUCTION}

Diabetes is a multitude of disorders in the entire metabolism, including not only protein, lipids, and carbohydrates, but also the electrolytic and acid-basic ones. The summary of urine and urinary sediment may also reflect these changes at the level of different parameters. What we are going to investigate is how different degrees of decompensation of diabetes will cause more or less significant variations in a usual analysis, but as important 
as the summary together with urinary sediment. A well or poorly controlled diabetes can the evidence by the glycosylated hemoglobin, which ensure a long-term (4 months) assessment of the average glucose levels and implicitly a good monitoring of the treatment taken or of the continued dietary regime. The action of this valuable indicator of the metabolic glucose control, which is the glycosylated hemoglobin, is explained biochemically by the fact that glucose, being a reactive molecule, can be linked to the terminal nitrogen of the $B$ chain of hemoglobin. $98 \%$ of adult hemoglobin is $\mathrm{Hb}$ type $\mathrm{A}$, and $7 \%$ of $\mathrm{HbA} 1$ by glycosylation forms hardly reversible bonds. HbAlc is the component with the highest glucose affinity and most accurately measures glycosylated hemoglobin $(1,2)$.

Another important aspect would be that, this reaction being non-enzymatic the amount of glycosylated hemoglobin depends on the average blood glucose levels but also on the lifespan of the red blood cells, which under normal conditions is 120 days. We therefore expect that, regardless of average blood glucose levels, we may meet increased levels of glycosylated hemoglobin and in other conditions, such as Fe deficiency anemia, in uremic or dyslipidemic patients, as it is possible in other conditions such as hemolytic anemia, chronic kidney failure or chronic bleeding, may occur falsely low values of this parameter without directly related to the average blood glucose level $(1,2)$.

For a good interpretation of this parameter, it is necessary to exclude all possible causes that could distort this result, being possible associated diseases, listed above.

\section{MATERIALS AND METHODS}

In this study we will perform a comparative analayses between two groups of patients with diabetes, one well controlled sugar with a level of $\mathrm{HbA} 1 \mathrm{c}<7 \%$ and the other poorly controlled with a level $>7 \%$ of HbAlc. The groups of patients were investigated at the medical analysis laboratory "Sfantul Dimitrie" Hospital, from Targu Neamt, during 2019, these are monitored at the outpatient diabetes office of the same hospital.

The group with poorly controlled diabetes is made up of 109 patients, and the wellcontrolled group of 105 patients. As material we used biological samples representing the summary and the urinary sediment for both groups, differentiating between them having made the glycosylated hemoglobin. The HbAlc is determined with the help of a Clover A1c Self device, which carries out a daily check that indicates the validity of the equipment and a monthly check used as an internal control that assures the validity of the results obtained. (3)

The principle used for this determination is photometric for both, total and glycosylated hemoglobin. For the examination of the urine summary, the Dirui H-500 urine analyzer was used, which adopts the principle of photoelectric color comparison to test the amount of biochemical components according to the chromatic modification caused by the reaction of the urine analysis bands with the biochemical components in the urine. The instrument uses 4 types of monochrome light to scan areas of regents one after another, and the scanning system converts the optical signal into an electrical signal. Also in the case of the urine summary, daily normal and pathological internal control is used. When examining the urine summary, the following parameters are investigated: density, $\mathrm{pH}$, leukocytes, red blood cells, bilirubin, urobilinogen, ketone bodies, proteins, glucose, nitrites. To obtain the urinary sediment the urine summary is centrifuged at $5000 \mathrm{rpm}$ for 5 minutes followed by the sediment being examined under the Nike microscope with objective 20 (4).

\section{RESULTS AND DISSCUSIONS}

On the gender distribution of the wellcontrolled diabetes group, a difference can be observed between the two sexes with a female predominance, $60.57 \%$ compared to $45.43 \%$ males. (Figure 1) 
Bulletin of Integrative Psychiatry O New Series OJune 2020 ○ Year XXVI ONo. 2 (85)/47

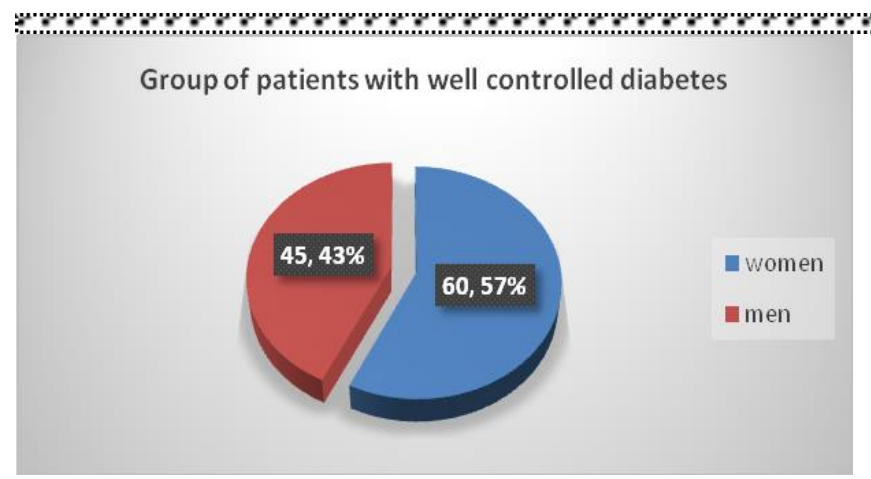

Figure 1- The influence of gender in the group with well-controlled diabetes

On the gender distribution of the poorlycontrolled diabetes group, a difference can be observed between the two sexes with a predominance of females, $58 \%$ compared to $42 \%$ males, situation similar to that of the well-controlled group diabetes (Figure 2).

\section{Group of patients with poorly controlled diabetes}

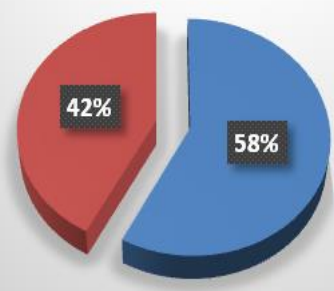

women

vmen

Figure 2- The influence of gender in the group with poorly-controlled group

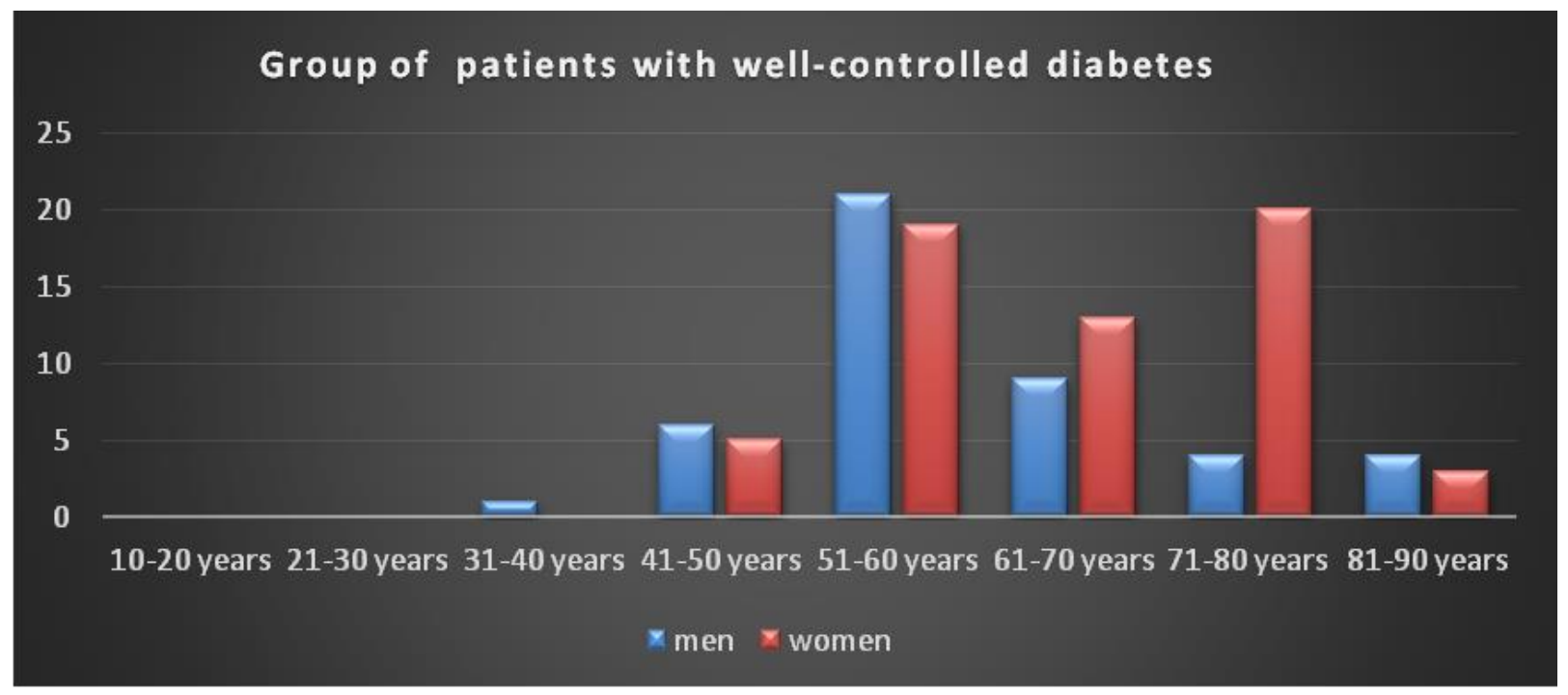

Figure 3- Age distribution in the well-controlled diabetes group

On the age distribution, in the group of patients with well-controlled diabetes, as can be seen in the chart above, in the case of men, predominates the age group between 51 and 61 years compared to that of women, in which predominates the age group between 71 and 80 years and less so in younger age groups.

(Figure 3) 


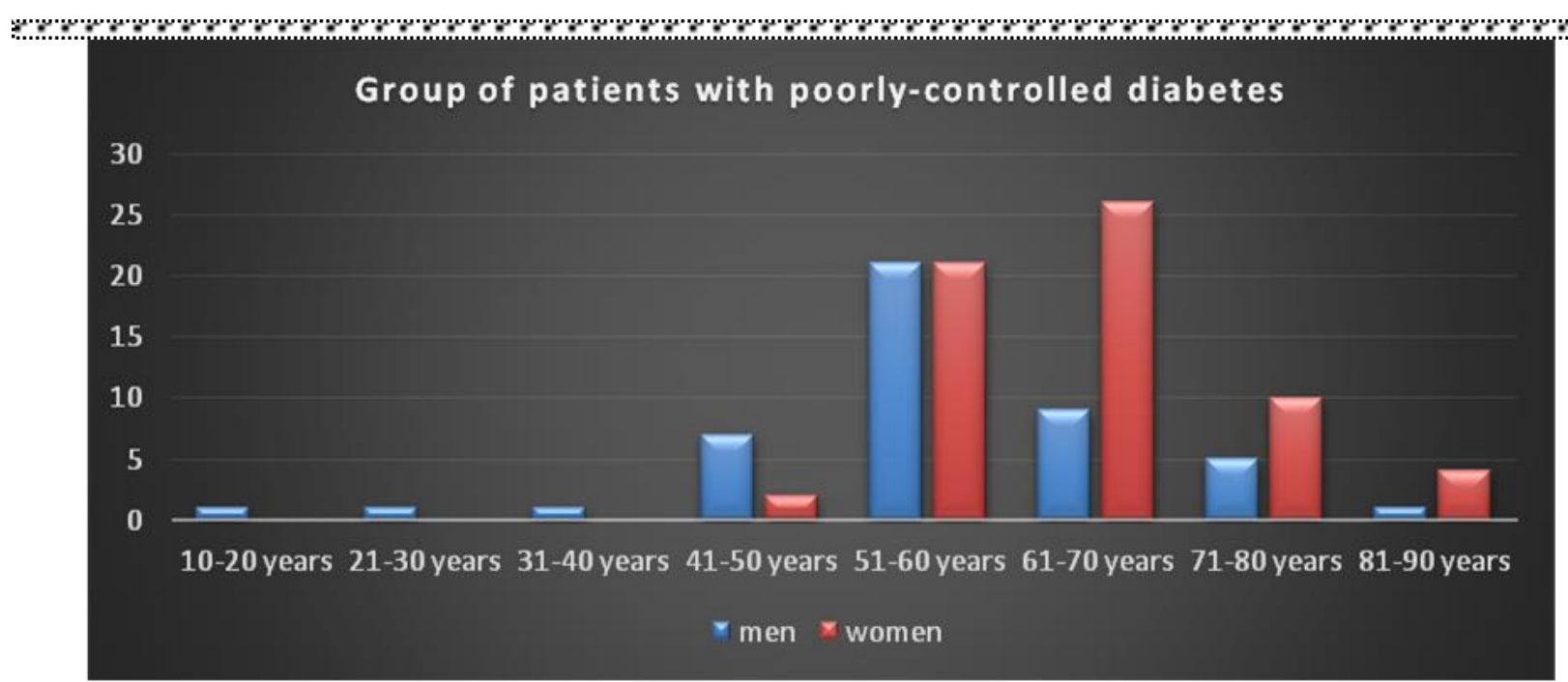

Figure 4- Age distribution in the poorly-controlled diabetes group

On the age distribution, in the group of patients with well-controlled diabetes, as can be seen in the chart above, in the case of men, predominates the age group between 51 and 61 years compared to that of women, in which predominates the age group between 61 and 70 years and less so in younger age groups (Figure 4)
Comparing the parameters of the urine summary, between the two groups, well and poorly controlled diabetes, a major difference can be observed in the urinary glucose, following the parameters: urinary density, nitrites and albumin. Small differences exist between parameters: $\mathrm{pH}$, red blood cells, ketone bodies, and at the level of leukocytes and urobilinogen the differences are almost non-existent (Figure 5).

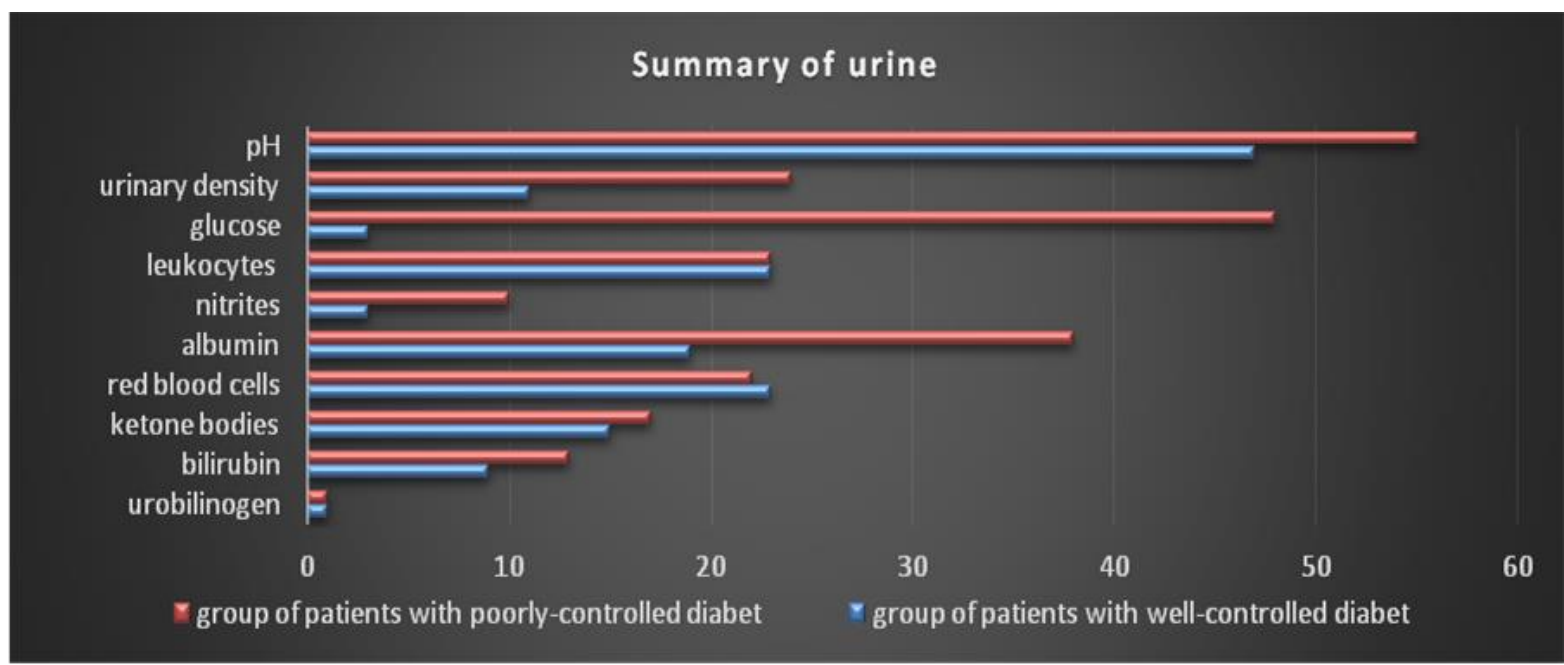

Figure 5- The variation of urine summary parameters in the group of patients with well-controlled diabetes and in the group of patients with poorly-controlled diabetes.

Urobilinogen is increased in $1 \%$ of the people in both groups. Urobilinogen is elevated under conditions of haemolytic jaundice and hepatic impairment, unrelated to the underlying condition, being associated with comorbidities. The graphical representation does not show significant differences between the two groups.

Bilirubin shows increases in $9 \%$ of patients in the group with well-controlled diabetes and $15 \%$ in the poorly controlled group. In this case, we did not discuss a connection with the basic diagnosis of the variation of this parameter. The comparation between the two 
lots is presented in the chart above. The presence of urinary bilirubin, being only conjugated bilirubin, indicates a sign of early liver damage or possible intra- or extrahepatic obstruction. The graphical comparision shows us an insignificant difference between the two groups $(5,6)$.

The ketone bodies meet with a frequency of $15 \%$ in the case of the well-controlled group and $17 \%$ in the case of the poorly controlled one. The graphical comparison shows us an insignificant difference between the two groups. The ketone bodies appear in the urine in the conditions of altered carbohydrate metabolism, when the intake of carbohydrates is restricted, in diets high in fat and protein, inanity, anorexia, dyspeptic states, eclampsia, glycosuria, fever, pregnancy, lactation. It can also be found in non-diabetic people, in acute infections, stress or physical exertion $(5,6,7)$.

The presence of red blood cells (lysed or nonlysed) shows in 23\% of cases of diabetes well controlled and in $25 \%$ respectively in the poorly controlled ones and in this case not being important differences. Lysed red blood cells release free hemoglobin, a situation that we discuss hemoglobinuria. In the case of unlicensedred blood cells hemoglobin remains in the erythrocyte content: in this case we are dealing with hematuria $(6,7)$.

Hemoglobinuria occurs in intravascular hemolysis or as a result of lysis of red blood cells in the urinary tract. Hematuria is found in disorders of the kidney and urogenital tract: lithiasis, glomerulonephritis, renal tumors, bladder tumors, cystitis, pyelonefritis, prostate adenoma, trauma, polycystic kidney, renal infarction. $(5,6,7)$.

Another useful parameter in the early diagnosis of diabetes but also in its monitoring are urinary proteins. The test has a higher sensitivity to albumin than to other types of protein. $18 \%$ of the patients in the well-controlled group have proteinuria compared to $41 \%$ in the case of the poorlycontrolled group, the differences being observed in the graph above. This parameter can also be positive in other situations unrelated to diabetes: in case of renal injury (glomerulonephritis, tumors, lithiasis, TBC, nephrotic syndrome), in the case of infectious conditions, heartmfailure, acute pulmonary edema, febrile states. Also it can meet in conditions of intense effort, prolonged orthostatic) stationary, tiredness.

The presence of nitrites is specific for bacteuria, based on the conversion of nitrate into nitrite under bacterial action. There are also bacteria that do not form nitrites (enterococci, staphylococci, piocyanic) situation in which the urinary tract infection is present and in the absence of nitrites. In the case of the group of well controlled diabetics, $3 \%$ have a positive nitrite reaction, and $10 \%$ appear in the poorly controlled ones. The graphic represantion is in the chart above.

Leuckocituria, another identified parameter is present in $23 \%$ of patients with wellcontrolled diabetes and $22 \%$ in those of the other groups as seen from the two graphical represantations above. This test detects both, intact, lysed leukocytes, and leukocyte cylinders. The leuckocyturia may be the indication of a bacterial infection of the urinary tract, but also of a viral or parasitic infection. In the case of a chronic inflammation, leukocystis frequently results in the absence of bacteriuria. This situation can be found in tumors or TBC. Leukocyturia can also mark other inflammatory conditions without a bacterial, viral or fungal etiology: glomerulopathies, intoxications, analgesicinduced nephropathy.

Urinary glucose is identified in $3 \%$ of the group with well-controlled diabetes and is found in proportion of $50 \%$ in the poorlycontrolled group, the significant difference being shown in the graphs above. Glycosuria appears not only in diabetes but also in other conditions: hyperthyroidism, Cushing's disease, pancreatic or liver disease. Glycosuria also depends on the renal glucose elimination threshold, there are pathological situations in which this threshold shows a decrease.

Another important parameter is the urinary 
ндндн

density: in $11 \%$ of cases there is increase of $>1030$ in the well-controlled group and $22 \%$ in the other group. The difference between the two groups appears in the chart above. This test detects the concentration of ions in the urine. Urinary hypertension (increased urinary density higher than 1022) can be found not only in diabetes, but also in the case of proteinuria, some water loss (in the case of sweating, vomiting, fever, diarrhea).

In the case of $\mathrm{pH} 46 \%$ of the patients in the well-controlled group present low $\mathrm{pH}$ and in the poorly controlled group this percentage rises to $50 \%$ as shown in the graphs above. The decrease in $\mathrm{pH}$ occurs in various physiological situations such as: during sleep, starvation or a diet high in meat and protein, but it is may also be found in the administration of diuretics, respiratory acidosis, metabolic acidosis, renal failure with decompensation, TB, urinary tract infections $(5,6,7)$.

What we could also mention in this context is the fact that lately there is an increased interest in the so-called "Type 3 diabetes", which is a term that has been proposed for Alzheimer's disease that results from chronic insulin resistance in the brain. (8)

Thus, it was point out that insulin resistance and insulin (as a growth factor) are an essential part of Alzheimer's disease progression. (9) Although type 1 diabetes and type 2 diabetes are characterized by hyperglycemia, Alzheimer's disease can develop without the presence of significant hyperglycemia inside the brain. Many patients with type 2 diabetes have deposits of proteins, called amyloid beta in their pancreas, similar to the deposits of proteins found in the brain tissues of people with Alzheimer's disease (10).

Type 2 diabetes is a condition characterized by the body's insulin resistance or relative insulin deficiency. Insulin deficiency and resistance are closely linked to the phosphorylation of $\tau$ brain protein (10) and the production of $\beta$ amyloid protein at the neuronal level, both processes being responsible for the start of Alzheimer's disease. Type 2 diabetes along with obesity, metabolic syndrome and hyperinsulinemia could be risk factors in the occurrence of this neurodegenerative disease, recently called "type 3 diabetes" $(11,12,13)$.

Alzheimer's disease, progressive neurodegenerative disease, the most common form of senile dementia, is correlated with the aging process. The pathology mainly affects the cortical atria involved in memory and cognition. Changes in the brain are phosphorylation of cytoskeletal filaments and storage of amyloid plaques in neurons (14).

While there are three hypotheses in the mechanism of Alzheimer's disease, such as Cholinergic hypothesis when the level of a neurotransmitter, acetylcholine, is decreased due to a deficiency of choline-acetylase in the formations involved in cognitive functions; Beta amyloid accumulation hypothesis; cleavage of APP precursor protein (amyloid precursor protein) with $\beta$ amyloid formation, a cytotoxic compound with proapoptotic effects. Excess storage is favored by the major risk genetic in the onset of familial Alzheimer's disease, namely apolipoprotein $\varepsilon 4$ (Apos4)(15)(16) or the hypothesis of alteration and accumulation of $\tau$ protein was demonstrated by the study of pathological intraneuronal clusters, formed by the posthyperphosphorylation of $\tau$ protein, without knowing exactly whether it has a causal or a secondary value, the disease is revealed by damage to nerves and brain cells, and the first signs we can recognize it are confusion, difficulty speaking and forgetting (17).

More evidences points to the possibility that Alzheimer's disease is, in fact, a metabolic disorder, the result of inappropriate diets and not a genetic or strictly neurological problem. Insulin is the natural hormone that causes blood sugar to be absorbed by the liver, muscle and adipocytes. Type 2 of diabetes is caused by an excess of blood glucose, resulting from either a deficiency in the production of insulin in the pancreas or a resistance to its signals by organs that 
r m

naturally take up the glucose (18). Among people who may develop Alzheimer's disease are people with type 2 diabetes, people with obesity or those with metabolic syndromes, the latter representing a complex of dietrelated pathologies $(19,20)$.

After post-mortem experiments on bodies, it was found that the brains of those who died due to Alzheimer's disease had a very low level of insulin and insulin-based growth factors compared to the brains of those died other causes.

As a result, it was concluded that insulin and similar growth factors are produced in the brain not only in the pancreas, where they have several functions: regulating the transmission of signals between neurons, neurons that whose influence growth, plasticity and survival.

\section{CONCLUSIONS}

In the composition of both groups, the well -controlled and the poorly controlled one, the predominance of the female sex is noted. The distribution by age group shows us a ranking in the first place of the age group 51-60 years in the case of well-controlled group, instead in the case of the poorly-controlled group, this place is owned by the age group 61-70 years. There are very small difference between the two groups in the case of the parameters: urobilinogen, bilirubin, ketone bodies, red blood cells, leukocytes. In urobilinogen the percentage in $0.9 \%$ in both groups. In bilirubin the percentage is $11 \%$ compared to $8 \%$ in favor of the poorly controlled group.

Even in the case of ketone bodies the percentage are close: $15 \%$ in the poorly controlled group compared to $14 \%$ in the well-controlled one, considering that the presence of ketone bodies in the urine is also related to physiological situations. In the case of leukocytes, the percentage is identical for both groups: $21 \%$, and for the red blood cells the percentages are $20 \%$ in the poorly controlled and $21 \%$ in the well-controlled one. In the case of nitrites, there is a slightly higher percentage in the case of the poorly controlled group $9 \%$ compared to $2 \%$ in the case of the well-controlled group, being a parameter associated to a large extend with bacteriuria. A large proportion of patients in both groups decrease in urine $\mathrm{pH}: 50 \%$ in the poorly controlled group and $44 \%$ in the wellcontrolled group, the increased acidity being a constant of this condition manifested also in the urinary level.

A difference also occurs in the case of urinary density: $22 \%$ of the patients in the poorly controlled group show increases of this parameter compared to $10 \%$ in the well-controlled group. The largest differences occur in the case in the case of urinary albumin growth: $34 \%$ in the poorly controlled group and $17 \%$ in the well-controlled group. There is a clear difference between the two groups for urinary glucose: $44 \%$ of the patients in the poorly controlled groups show increases compared to $2 \%$ in the well-controlled group. In the case of urinary sediment only in the case of leukocytes and microbial flora there is a slight increase in favor of the poorly controlled group: in leukocytes the percentage is $30 \%$ compared to $24 \%$ and the microbial flora is found in a proportion of $22 \%$ and $15 \%$ to the well-controlled group. In the case of the other pathological elements of the urinary sediment: red blood cells, calcium oxalate crystals, uric acid crystals, granulose, hyaline or leukocytes cylinders, there are no differences between the two groups.

As mentioned this could be further correlated with the latest results describing Alzheimer's disease as the called "Type 3 diabetes", which is a term that has been proposed for Alzheimer's disease, based mainly from chronic insulin resistance in the brain, as our group is planning to study in the near future.

\section{ACKNOWLEDGEMENTS AND DISCLOSURES}

The authors state that they are no declared conflicts of interest regarding this paper. 


\section{REFERENCES}

1. Compendiu bibliografic pentru rezidentiat, vol. II. Editura medicala, 1995.

2. Colev Luca V. Fiziopatologia generala. Editura Grigore T. Popa, Iasi, 2000.

3. Manual de instructiuni pentru Clover H-500.

4. Manual de instructiuni penrtu Dirui H-500.

5. Analize de laborator si alte explorari diagnostice. Editura MedicArt, 2007.

6. Wallach J. Interpretarea testelor de diagnostic. Editura Stiintelor Medicale, 2005.

7. Foia L. Corelatii clinice in interpretarea parametrilor biochimici. Editura Junimea, Iasi, 2010.

8. Steen E, Terry BM, Rivera EJ, Cannon JL, Neely TR, Tavares R, Xu XY, Wands JR, de la Monte SM. Impaired insulin and insulin-like growth factor expression and signaling mechanisms in Alzheimer's disease is this type 3 diabetes? J Alzheimers Dis. 2005;7(1):63-80.

9. Schubert M, Gautam D, Surjo D, Ueki K, Baudler S, Schubert D, Kondo T, Alber J, Galldiks N, Küstermann E, Arndt S, Jacobs AH, Krone W, Kahn CR, Brüning JC. Role for neuronal insulin resistance in neurodegenerative diseases. Proc Natl Acad Sci U S A. 2004;101(9):3100-3105.

10. Drăgan GR, Ciocoiu M. Mecanismele patogenice implicate în demenţa Alzheimer: proteina tau şi acumularea de beta amiloid. În: Clasic şi modern în fiziopatologie: o abordare integrativă în educaţie şi cercetare. Sub redacţia Bădescu MM. Iaşi: Editura „Gr. T. Popa”, U.M.F; 2015; 146-150.

11. Li S, Song D, Leng SX. Link between type 2 diabetes and Alzheimer's disease: from epidemiology to mechanism and treatment. Clin Interv Aging. 2015; 10:549-560.

12. Janson J, Laedtke T, Parisi JE, O'Brien P, Petersen RC, Butler PC. Increased risk of type 2 diabetes in Alzheimer disease. Diabetes. 2004;53(2):474-481.

13. Nicolls MR. The clinical and biological relationship between type II diabetes mellitus and Alzheimer's disease. Curr Alzheimer Res. 2004;1(1):47-54.

14. Wang XP, Ding HL. Alzheimer's disease: epidemiology, genetics, and beyond. Neurosci Bull. 2008;24(2):105109.

15. Craft S, Asthana S, Cook DG, Baker LD, Cherrier M, Purganan K, Wait C, Petrova A, Latendresse S, Watson GS, Newcomer JW, Schellenberg GD, Krohn AJ. Insulin dose-response effects on memory and plasma amyloid precursor protein in Alzheimer's disease: interactions with apolipoprotein-E genotype. Psychoneuroendocrinology. 2003;28(6):809-822.

16. Irie F, Fitzpatrick AL, Lopez OL, Kuller LH, Peila R, Newman AB, Launer LJ. Enhanced risk for Alzheimer disease in persons with type 2 diabetes and $A P O E \varepsilon 4$ : the Cardiovascular Health Study Cognition Study. Arch Neurol. 2008; 65:89-93.

17. Hoyer S, Lannert $\mathrm{H}$. Inhibition of the neuronal insulin receptor causes Alzheimer-like disturbances in oxidative/energy brain metabolism and in behavior in adult rats. Ann N Y Acad Sci. 1999; 893:301-303.

18. Schubert M, Brazil DP, Burks DJ, Kushner JA, Ye J, Flint CL, Farhang-Fallah J, Dikkes P, Warot XM, Rio C, Corfas G, White MF. Insulin receptor substrate-2 deficiency impairs brain growth and promotes tau phosphorylation. J. Neurosci. 2003;23(18):7084-7092.

19. K.L. Hildreth, R.E. Van Pelt, R.S. Schwartz Obesity, insulin resistance, and Alzheimer's disease Obesity (Silver Spring), 20 (2012), pp. 1549-1557.

20. Kivipelto M, Ngandu T, Fratiglioni L, Viitanen M, Kåreholt I, Winblad B, Helkala EL, Tuomilehto J, Soininen H, Nissinen A. Obesity and vascular risk factors at midlife and the risk of dementia and Alzheimer disease. Arch Neurol. 2005 Oct;62(10):1556-60.

\section{Correspondence:}

Daniel Timofte,

MD, PhD, professor, Grigore T.Popa” University of Medicine and Pharmacy, 16, Universităţii Street, 700115, Iasi, Romania, dantimofte@yahoo.com 